\title{
Self-Management Education Program and Metabolic Indicators in Type 2 Diabetes at Zagazig University Hospital, Egypt: An intervention study.
}

\author{
${ }^{1}$ Hussein M. Salama, ${ }^{2}$ Walaa S. Fouad and ${ }^{3}$ Mona H. Ibrahim \\ ${ }^{1}$ Internal Medicine Department, ${ }^{2}$ Family Medicine Department, ${ }^{3}$ Community, Environmental \\ and Occupational Medicine Department Faculty of Medicine, Zagazig University, Egypt.
}

Submission Date: 2020-11-16 Revision Date: 2020-12-07 Acceptance Date: 2020-12-07

\begin{abstract}
Background: High-quality diabetes self-management education has been shown to improve patient self-management, satisfaction, and glucose outcomes. Objective: this study aimed to assess the effect of self-management diabetes education program on metabolic control indicators among type 2 diabetes mellitus patients. Method: An interventional randomized controlled trial was carried out at an outpatient diabetes clinic in a tertiary level hospital, Egypt. A total of 76 adult type 2 diabetic patients were recruited, 70 (92.1\%) patients completed the study. In pre and post-intervention phases, data were collected to assess; sociodemographic characteristics; metabolic indicators; glycosylated hemoglobin in both groups at the beginning of the study and 3 months after the intervention. In the intervention phase, a self-management $5 \mathrm{~A}$ model was applied to the intervention group while the traditional group continued routine treatment and traditional health education. The effects on metabolic indicators were assessed between groups after the intervention. Results: At baseline, both intervention and traditional groups were matched regarding risk factors of diabetes and sociodemographic characteristics. Glycosylated hemoglobin and other metabolic parameters showed no significant differences between both groups before intervention. This study revealed significant improvement in metabolic indicators after intervention among the intervention group compared to the traditional one regarding fasting blood glucose level, HbA1C level, total cholesterol, and other lipoproteins as well respectively. Diabetes selfmanagement questionnaire scores were significantly improved after intervention among cases compared to controls $(\mathrm{p}<0.001)$. Conclusion: This study explored the effectiveness of using the $5 \mathrm{~A}$ model of self-management in improving metabolic control indicators in type 2 diabetic patients.
\end{abstract}

Keywords: T2DM, self-management, 5 A model, metabolic indicators, Egypt, HbAlC.

Corresponding author: Hussein M. Salama mail: monhamed@yahoo.com

\section{Introduction}

Diabetes mellitus (DM) is one of the major health problems of the $21^{\text {st }}$ century. Diabetes is among the top 10 causes of death globally and together with the other three major non-communicable diseases (NCD) represent more than $80 \%$ of all premature chronic disease mortality. It affects about 425 million people worldwide $(8.8 \%$ of adults aging from 20 79 years) and by the year of 2045, about 629 million of people (20-79 years) will have diabetes. ${ }^{1}$

The prevalence of type 2 diabetes (T2D) in Egypt is high affecting about $15.6 \%$ of all 
adults aged (20 to 79 years old). ${ }^{2}$ It is expected that their number will grow from 8.2 million in 2017 to 16.7 million in 2045 so; Egypt was listed among top ten countries globally in diabetes prevalence according to international diabetes federation (IDF). ${ }^{1}$

Because this adverse impact on health and health care cost so, it is the most demanding situation to the health care providers and active participation of patients. $^{3}$

Uncontrolled hyperglycemia in T2DM patients is associated with serious multiple long-term micro-vascular and macrovascular complications. Physical inactivity, unhealthy eating habits, medication nonadherence, and lack of regular blood glucose monitoring factors linked to them. ${ }^{4}$ DM self-management education (DSME) and support is highly effective in establishing and implementing the principles of diabetes care. ${ }^{5}$ DSME improve Patient diabetes knowledge, DSM behaviors, adherence to medications, selfefficacy, and quality of life. ${ }^{6}$ Several metaanalyses have demonstrated that DSMES is associated with clinical benefits in persons with T2DM. ${ }^{7}$

Traditional teaching methods, which lack the patients' active cooperation, are predominant in diabetic patient's education programs so that they have little clinical value. ${ }^{8}$

Different models of selfmanagement/education create suitable strategies for changing behavior such as five A model, known as behavior change counseling model is an evidence-based approach for health promotion and behavior change. ${ }^{9}$

In the view of the previously mentioned literature, beside absence of previous studies about self-management education model were done in the place of the study. Therefore, the researchers aimed to assess effect of behavior change counseling model on metabolic control indicators among T2DM patients.

\section{Method}

An interventional single blind randomized parallel controlled trial was carried out, with equal parallel randomization for the study and the control group in the period from the onset February 2019 to the end of May 2019.

The study was conducted in the outpatient specialized clinic of diabetes at a tertiary level hospital, Sharkia governorate, Egypt. Diabetic patients with T2DM who attended the outpatient clinic of diabetes at Zagazig University Hospital during the period of the study.

Patients who meet the World Health Organization diagnostic criteria of T2DM, possessed a certain ability of learning, willing to participate in small group education sessions, capable of independently performing activities of daily living, age above 18 years old and gave an informed consent were included. Patients, who were pregnant, with gestational diabetes, had history of malignancy, severe mental health problems, or sever complications, participants who did not attend the classes more than one session were excluded from the study.

Sample size was estimated to be (76) patients, 32 patients in each group and by assuming $20 \%$ attrition rate, so the final sample size was 38 patients in each group. Depending on the mean level of fasting blood sugar (FBS) (mg/dl) post intervention in study compared to control groups from previous study $(126 \pm 67$ and $196 \pm 120$ ) respectively, [8] at confidence interval $95 \%$ and power of test $80 \%$ using Epi Info 7 program.

The files of the participants were selected by simple random method then divided to 
even and odd numbers, and randomly allocated them by flib the coin method where odds numbers files were allocated to the intervention group and marked by red colored stickers and those with even numbers were allocated to the traditional group and marked by green colored stickers for easy follow-up. Figure 1 shows CONSORT Flow of the study participants.

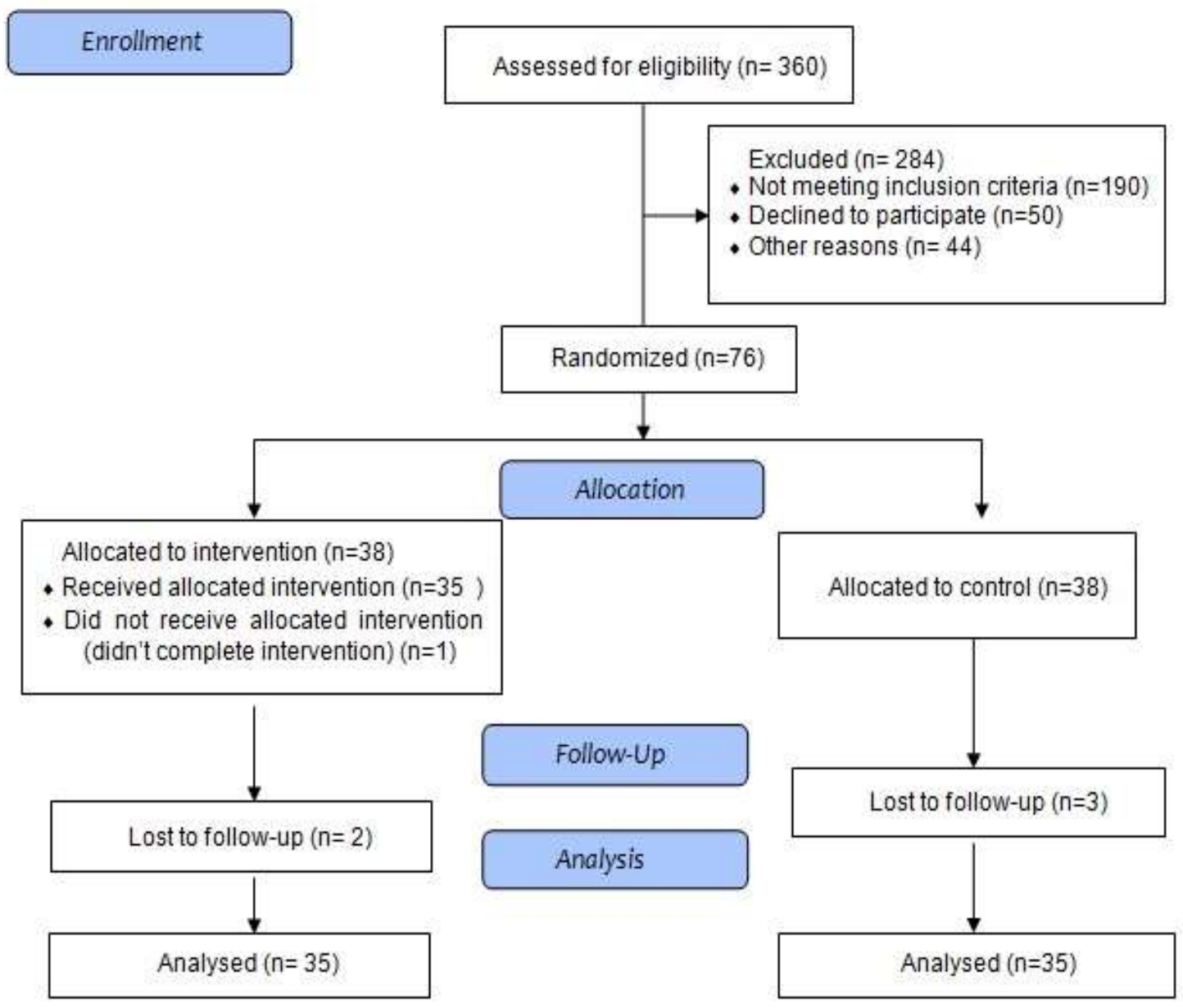

Figure (1): CONSORT Flow of the study participants.

Data collection tools: All the studied patients were subjected to:

First and third phases (Pre and postintervention):

1- Face-to-face interview was done by researchers to collect data about:

Socio demographic characteristics included; age, gender, residence, level of education, occupation, marital status and income.

Present history about; duration of DM, type of medication, presence of complications, blood glucose monitoring and associated co morbidities; family history of DM and consanguinity; any health problems.

2- Assessment of compliance to therapy was assessed at the beginning of the study and after 3 months through measuring fasting blood sugar and hemoglobin A1C. 3- Weight and height of every patient were measured and BMI was calculated at the beginning of the study and after 3 months by the formula $(\mathrm{BMI}=$ weight $(\mathrm{Kg}) /$ height $\left(\mathrm{m}^{2}\right)$. 
4- The blood tests were conducted at the Zagazig University Hospital Laboratory at the beginning of the study then after 3

Table (1): Socio-demographic characteristics of the studied groups.

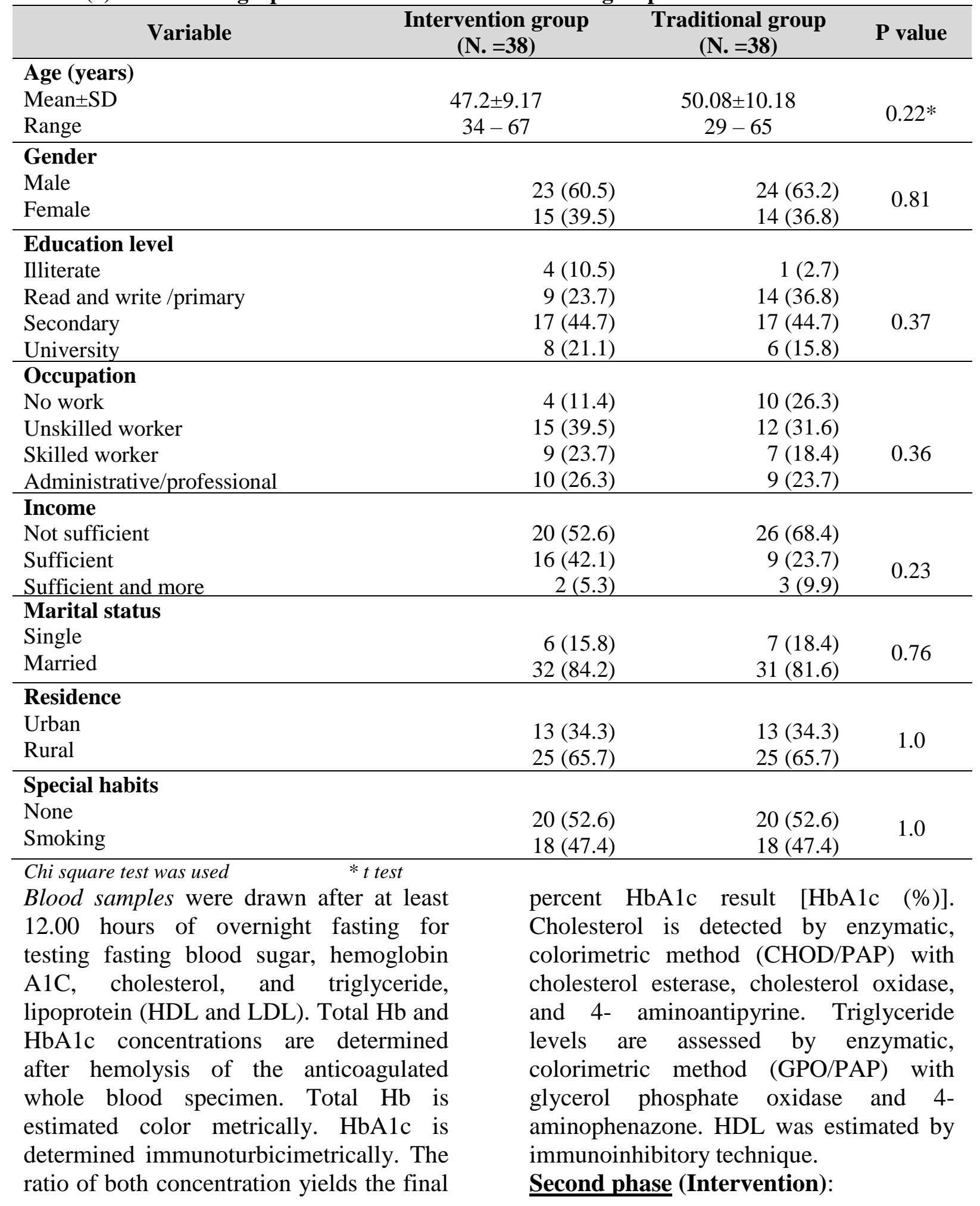

months at the same time point as the questionnaire assessment were conducted. 
Expected outcome of the study: The traditional group continued routine treatment and received traditional health Table (2): Comparison of the metabolic indicators between both groups before and after the intervention.

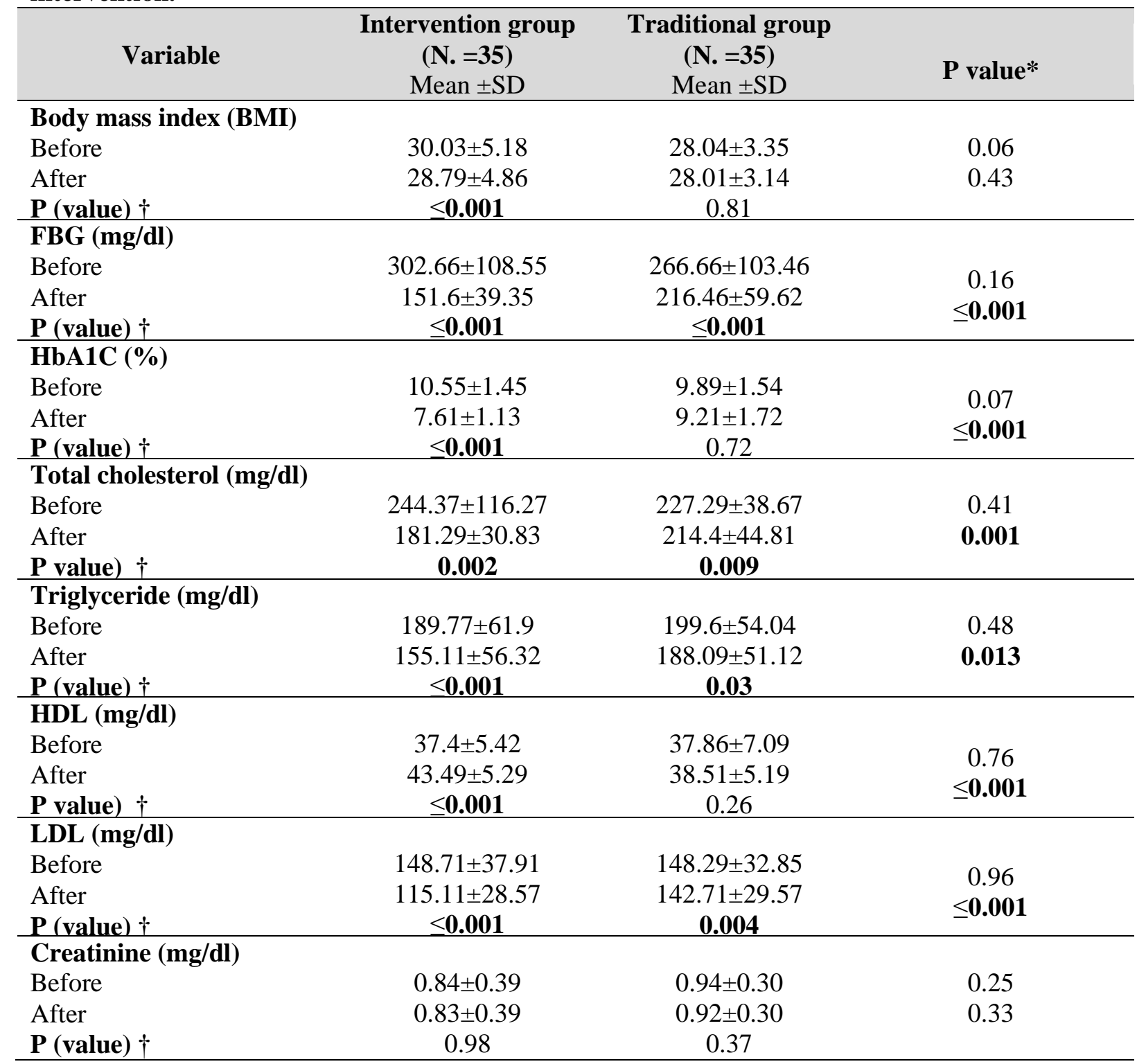

FBG: fasting blood glucose, HbA1C: hemoglobin AlC, HDL: High density lipoprotein, LDL: Low density lipoprotein. $广$ : Paired $t$ test used for comparison between each group (before and after intervention). *: t test between both study and control groups.

The intervention group had a combination of mostly individual patient education and group health education sessions of three to four individuals were held for patients if the identified problems were common among them. These sessions for health education program were applied by the education which imparts knowledge to the patient.

Body mass index (BMI)

Before

$30.03 \pm 5.18$

$P$ (value) $t$

0.81

\begin{tabular}{l} 
Before \\
After \\
$\mathbf{P}$ (value) $\dagger$ \\
\hline HbA1C $(\%)$
\end{tabular}

The Egyptian Journal of Community Medicine

Vol. 39

No. 3

July

2021

researcher to the participants in the model group attending the diabetes outpatient clinic in Zagazig University Hospital during study period. The program duration was three months and included six sessions: once a week for 1 hour in the 
first four weeks, then monthly for the second and third months.

A self-management model called 5A model was applied during three months of

Table (3): Comparison of diabetes self-management questionnaire (DSMQ) scores before and after intervention of study group.

\begin{tabular}{lccc}
\hline \multirow{2}{*}{ Variable } & \multicolumn{3}{c}{$\begin{array}{c}\text { Intervention group }(\mathbf{N} .=35) \\
\text { Mean } \pm \text { SD }\end{array}$} \\
\cline { 2 - 4 } & Before & after & P value $\dagger$ \\
\hline Diabetes self- $\quad$ management & $12.16 \pm 6.93$ & $28.76 \pm 6.36$ & $\leq \mathbf{0 . 0 0 1}$ \\
questionnaire score (DSMQ) & & $6.89 \pm 1.89$ & $\leq \mathbf{0 . 0 0 1}$ \\
\hline Glucose management score & $3.29 \pm 1.68$ & $6.92 \pm 1.88$ & $\leq \mathbf{0 . 0 0 1}$ \\
Diet control score & $3.16 \pm 1.87$ & $6.37 \pm 1.6$ & $\leq \mathbf{0 . 0 0 1}$ \\
Physical activity score & $2.51 \pm 1.71$ & $6.41 \pm 1.55$ & $\leq \mathbf{0 . 0 0 1}$ \\
Healthcare use score & $2.47 \pm 1.81$ & $2.2 \pm 0.72$ & $\leq \mathbf{0 . 0 0 1}$ \\
Sum self-care subscale score & $0.74 \pm 0.7$ & & \\
\hline
\end{tabular}

$\uparrow:$ Paired t test

1- In the $1^{\text {st }}$ stage (Assess): the patients were interviewed and their behavior on insulin injection, use of hypoglycemic drug, blood sugar self-monitoring, exercise/physical activity and dietary habits were assessed by using Diabetes Self-Management Questionnaire (DSMQ). ${ }^{10}$

2- In the 2nd stage (Advice): All the abnormal or unexpected findings obtained from the assessment stage were reviewed with the patients. Also, provide information about personal health risks and benefits of change.

3- In the 3rd stage (Agree): mutual contribution of patients and health care provider on setting realistic goals based on the patient's interest and confidence in their ability to change the behavior.

4- In the fourth stage (Assist): help anticipate barriers and develop practical applications based on the identified patient's strategies, problem-solving techniques and social/environmental support.

5- In the fifth stage (Arrange): Continued during the 12 weeks of the intervention, specify plan for follow-up (e.g., Visits, study period in the following stages based on each individual's needs.
Phone calls) and providing support in the course of follow up.

Primary outcome: degree of improvement in metabolic indicators of both groups after intervention. Secondary outcome: degree of change in DSMQ subscales among the intervention group after intervention. Factors associated with DSMQ subscales.

A pilot study was conducted to develop and check the questionnaire and test the response to different items of the questionnaire. Reliability and face validity of the questionnaire was assessed as well. No modification was done.

\section{Data analysis:}

Data was analyzed by IBM SPSS Statistics (IBM, Armonk, NY, USA) version 21.0, and using EPI- info version 7 for sample size calculation.

Shapiro walk test was used to test variance homogeneity. Mean and standard deviation (SD) were calculated for quantitative data, student $\mathrm{t}$ and paired $\mathrm{t}$ tests were used to detect significant differences between both groups and between each group before and after intervention respectively, where frequency and percentage were calculated for 
qualitative data, chi square test was used.

The test results were considered significant when p-value equal or less than 0.05 and all $\mathrm{p}$ values were two-tailed.

\section{Ethical Consideration}

Table (5): Univariate analysis comparing the relationship between diabetes self-management questionnaire (DSMQ) scores and socio-demographic and clinical data of Intervention group.

\begin{tabular}{|c|c|c|c|c|}
\hline variable & $\begin{array}{c}\text { Glucose } \\
\text { management } \\
\text { score }\end{array}$ & $\begin{array}{c}\text { Diet } \\
\text { control } \\
\text { score }\end{array}$ & $\begin{array}{c}\text { Physical activity } \\
\text { score }\end{array}$ & $\begin{array}{l}\text { Healthcare } \\
\text { use score }\end{array}$ \\
\hline \multicolumn{5}{|l|}{ Age (years) } \\
\hline$-<40$ years old $(\mathbf{n} .=9)$ & $6.74 \pm 1.68$ & $6.48 \pm 1.71$ & $6.04 \pm 2.01$ & $6.04 \pm 1.25$ \\
\hline$-\geq 40$ years old $(\mathbf{n} .=26)$ & $6.94 \pm 1.99$ & $7.08 \pm 1.95$ & $6.49 \pm 1.49$ & $6.53 \pm 1.64$ \\
\hline \multicolumn{5}{|l|}{ Gender } \\
\hline -Male (n.=21) & $6.41 \pm 1.81$ & $6.38 \pm 1.91 *$ & $6.18 \pm 1.55$ & $6.03 \pm 1.19$ \\
\hline -Female (n.=14) & $7.62 \pm 1.85$ & $7.74 \pm 1.58$ & $6.66 \pm 1.74$ & $6.98 \pm 1.87$ \\
\hline \multicolumn{5}{|l|}{ Education level } \\
\hline -Non university $(\mathbf{n} .=11)$ & $6.54 \pm 1.6$ & $6.51 \pm 1.7$ & $6.05 \pm 1.44$ & $6.76 \pm 1.05$ \\
\hline -University $(\mathbf{n .}=14)$ & $7.05 \pm 2.02$ & $7.11 \pm 1.97$ & $6.52 \pm 1.71$ & $6.24 \pm 1.73$ \\
\hline \multicolumn{5}{|l|}{ Occupation } \\
\hline -Not work $(\mathbf{n} .=4)$ & $7.66 \pm 1.59$ & $7.91 \pm 1.45$ & $6.66 \pm 0.91$ & $7.22 \pm 1.43$ \\
\hline -Worker $(\mathbf{n} .=31)$ & $6.79 \pm 1.93$ & $6.79 \pm 1.91$ & $6.34 \pm 1.7$ & $6.30 \pm 1.55$ \\
\hline \multicolumn{5}{|l|}{ Income } \\
\hline -Not sufficient $(\mathbf{n} .=\mathbf{1 9})$ & $6.73 \pm 2.04$ & $6.49 \pm 2.11$ & $6.19 \pm 1.79$ & $6.66 \pm 1.57$ \\
\hline -Sufficient (n.=16) & $7.08 \pm 1.61$ & $7.44 \pm 1.48$ & $6.59 \pm 1.43$ & $6.11 \pm 1.52$ \\
\hline \multicolumn{5}{|l|}{ Marital status } \\
\hline -Single $(\mathbf{n} .=5)$ & $6.95 \pm 1.75$ & $7.79 \pm 1.49$ & $7.82 \pm 1.92$ & $6.95 \pm 1.54$ \\
\hline -Married $(\mathbf{n . = 3 0})$ & $6.12 \pm 1.93$ & $6.73 \pm 2.02$ & $6.47 \pm 2.12$ & $6.74 \pm 2.03$ \\
\hline \multicolumn{5}{|l|}{ Residence } \\
\hline -Urban (n.=12) & $7.83 \pm 1.45 *$ & $7.9 \pm 1.44 *$ & $7.03 \pm 1.59$ & $6.29 \pm 1.85$ \\
\hline -Rural (n.=23) & $6.4 \pm 1.94$ & $6.41 \pm 1.9$ & $6.03 \pm 1.56$ & $6.47 \pm 1.41$ \\
\hline \multicolumn{5}{|l|}{ Duration of DM } \\
\hline$-<5$ years old $(\mathbf{n} .=19)$ & $7.33 \pm 2.04$ & $7.19 \pm 1.51$ & $6.43 \pm 1$ & $6.43 \pm 1.59$ \\
\hline$-\geq 5$ years old $(\mathbf{n .}=16)$ & $6.37 \pm 1.61$ & $6.61 \pm 1.94$ & $6.31 \pm 1.19$ & $6.38 \pm 1.54$ \\
\hline \multicolumn{5}{|l|}{ Family history of DM } \\
\hline - Yes $(\mathbf{n} .=17)$ & $7.01 \pm 1.57$ & $7.10 \pm 1.51$ & $6.59 \pm 1.69$ & $6.46 \pm 1.53$ \\
\hline - No (n.=18) & $6.77 \pm 2.19$ & $6.76 \pm 2.21$ & $6.17 \pm 1.58$ & $6.35 \pm 1.61$ \\
\hline \multicolumn{5}{|l|}{ Co-morbidities } \\
\hline - Yes $(\mathbf{n} .=18)$ & $6.96 \pm 1.62$ & $7.36 \pm 1.79$ & $6.85 \pm 1.49$ & $6.54 \pm 1.31$ \\
\hline - No $(\mathbf{n} .=17)$ & $6.82 \pm 2.19$ & $6.47 \pm 1.92$ & $5.88 \pm 1.65$ & $6.27 \pm 1.79$ \\
\hline \multicolumn{5}{|c|}{$\begin{array}{ll}\text { * Statistically significant at } p \text { value } \leq 0.05 \text {. } & \\
\text { participating patients was taken to be } & \text { A total } 76 \text { patients ( } 38 \text { in each group) were } \\
\text { enrolled in the study. The purpose of the } & \text { participated in this study. The attrition } \\
\text { study, voluntary participation, anonymity } & \text { made during interventions (one owing to } \\
\text { issues, confidentiality and freedom to } & \text { absence more than one session) and lost } \\
\text { discontinue at any time without being } & \text { follow-up (two from intervention group } \\
\text { exposed to any harm. } & \text { and three from traditional one due to refuse } \\
\text { Results } & \end{array}$} \\
\hline
\end{tabular}

The Egyptian Journal of Community Medicine

Vol. 39

No. 3

July

2021 Committee of the Faculty of Medicine, Zagazig University (ZU-IRB\#4995/12-22019). An informed written consent from 
so the completion rate of the study was 70 $(92.1 \%)$ in both groups.

At baseline, both intervention and traditional groups were matched as regard socio-demographic characteristics with no statistically significant differences between them. The mean age was $(47.2 \pm 9.17$ vs $50.08 \pm 10.18)$ years old, majority of patients were males $(60.5 \%$ and $63.2 \%)$, having secondary level of education $(44.7 \%)$, unskilled workers $(39.5 \%$ and $31.6 \%$ ), with insufficient income $(52.6 \%$ and $68.4 \%$ ), married (84.2\% and $81.6 \%$ ), with smokers $(47.4 \%)$ and living in rural areas $(65.7 \%)$ of both intervention and traditional groups respectively. (Table 1$)$

The mean duration of DM was $(6.73 \pm 6.89$ vs $8.67 \pm 6.92$ ) years of both intervention and traditional groups respectively, positive family history of DM was (47.4 vs $52.6 \%)$, majority of them had used combined oral therapy $(68.4 \%)$, free from ministry of health $(89.5 \%$ vs $92.1 \%)$, with hypertension as a co-morbidity $(47.4 \%$ vs $39.5 \%$ ) in both intervention and traditional groups respectively.

Both groups were matched regarding metabolic parameters with no statistical significant differences between them before intervention. However, this study revealed significant improvement in metabolic indicators after intervention among intervention group compared to traditional one regarding FBG level (151.6 \pm 39.35 vs $216.46 \pm 59.62 ; \mathrm{P}<0.001)$, HbA1C level $(7.61 \pm 1.13$ vs $9.21 \pm 1.72$; $\mathrm{p}<0.001)$, total cholesterol $(181.29 \pm 30.83$ vs 214.4 $\pm 44.81 ; \quad \mathrm{p}=0.001), \quad$ HDL $(43.49 \pm 5.29$ vs $38.51 \pm 5.19 ; \mathrm{p}<0.001)$ and LDL $\quad(115.11 \pm 28.57$ vs $142.71 \pm 29.57$; $\mathrm{p}<0.001)$ as well respectively. There was decrease in BMI of intervention group compared to traditional one after intervention but with no significant differences (28.79 \pm 4.86 vs $28.01 \pm 3.14$; $\mathrm{p}=0.43)$ and creatinine level $(0.83 \pm 0.39$ vs $0.92 \pm 0.30 ; p=0.33$ ) respectively. (Table 2 )

There were statistical significant improvements in all metabolic indicators of intervention group after intervention compared to pre-intervention $(\mathrm{p}=0.00)$ except for creatinine level $(\mathrm{p}=0.98)$. It is worth mentioning that there were statistical significant improvements in level of FBG $(\mathrm{p}<0.001)$, total cholesterol $(\mathrm{p}=0.009)$, triglyceride $(\mathrm{p}=0.03)$ and LDL $(\mathrm{p}=0.004)$ in traditional group after intervention compared to pre-intervention.

There were high statistical significant improvements in total diabetes selfmanagement questionnaire score and sub scores (glucose management, physical activity, diet control and healthcare use) of the intervention group before and after intervention $(\mathrm{p}<0.001)$. (Table 3$)$

There were no statistical signification associations between DSMQ scores with socio-demographic and clinical data of the study group except for diet control score was significantly higher among females $(7.74 \pm 1.58 \quad$ vs $6.38 \pm 1.91 ; \quad \mathrm{p}=0.03)$ compared to males and urban compared to rural residents $(7.9 \pm 1.44$ vs $6.41 \pm 1.9$; $\mathrm{p}=0.02$ ) respectively. Regarding glucose management score, it was significantly higher among urban than rural residents $(7.83 \pm 1.45$ vs $6.4 \pm 1.94)(\mathrm{p}=0.003)$. (Table 4)

\section{Discussion}

The aim of this study was to evaluate the effect of the 5A model self-management educational program on metabolic control parameters of patients with T2DM so an intervention single blind randomized controlled trial was carried out to assess its effects.

At baseline, the intervention and traditional groups were matched as regard socio-demographic characteristics, risk factors and metabolic indicators of 
diabetes with no statistically significant differences between the two groups before intervention.

Scarcity of studies applying 5A model makes it difficult to compare the results of this study with similar studies. Nonetheless, different sorts of selfmanagement have been utilized in different researches.

The present study revealed significant improvement of the two important glycemic control indicators including FBG and $\mathrm{HbA} 1 \mathrm{c}$ levels in the intervention group compared to traditional group after the intervention respectively $(\mathrm{P}=0.00)$. The improvement found between the two groups can be attributed to the selfmanagement model used in this study.

This was in line with Moattari et al. ${ }^{8}$ who recorded significant improvement as regard to FBG and hemoglobin $\mathrm{A} 1 \mathrm{C}$ in the experimental group compared to the control group in the experimental group after intervention respectively. Another study by Chai et al. demonstrated the efficacy of the educational program in improving diabetes self-care management skills and reducing FBS, HbA1C level. ${ }^{11}$ In addition, a similar study in Indonesia reported DSME had a positive impact on T2DM through reduction of blood glucose and $\mathrm{HbA} 1 \mathrm{c} .^{12}$

On the contrary, a study in Iran; showed that there were no significant differences for the $\mathrm{HbA} 1 \mathrm{C}$ between patient and control groups in the 3-month follow-up measurement as some patients refused to comply with some recommendations regarding self-care behaviors such as proper diet and physical activity because of fear of hypoglycemia but showed significant difference in HbA1C level between groups at 6 months follow-up. ${ }^{13}$ Another study in Kenya showed that six months of individualised DSME did not significantly improve the glycemic and metabolic control of the sub-optimally controlled type 2 diabetes patients. ${ }^{14}$ Comparing the results of the present study with these results highlights the value of the $5 \mathrm{~A}$ model in improving the glycemic control indicators.

Beside to the improvement of the glycemic control indicators, there was statistically significant improvement in nearly all metabolic parameters of type $2 \mathrm{DM}$ of intervention group compared to traditional group after intervention. These results signify the value of the $5 \mathrm{~A}$ model in management of diabetic patients which positively affect lifestyle and consequently clinical and laboratory parameters.

These results agree with Safabakhsh ${ }^{15}$ who applied the 5A model as a conceptual framework for the educational intervention used in study to determine its effect in post coronary bypass graft patients and his results showed that cholesterol, HDL and LDL and body mass index was improved after application of the model. In addition, study in Iraq showed that most DSME studies (60-80\%) could significantly improve total cholesterol, HDL-C, and TG of patients in intervention group (IG) compared to those in control group $(\mathrm{CG}){ }^{6}$ On the contrast, Sadegian et al. ${ }^{16}$ in India showed only an increase in risk of having high LDL among the control group, whereas there was no significant reduction in LDL in the intervention group. The difference was statistically significant $(\mathrm{P}=$ 0.001 ) and other parameters of lipid profile did not have any significant difference between two groups after 6 months. The differences of the population and their life style of this study and our study should not be disregarded. Another study in the United Kingdom ${ }^{17}$ showed a significant reduction in triglyceride levels at eight months $(\mathrm{P}=0.008)$ in the intervention group over the 12 months; but differences between them were not statistically 
significant. Moreover, everyone who consented to join the original trial ${ }^{16}$ was eligible for follow-up at three years in the DESMOND trial ${ }^{18}$ showed no statistically significant differences in lipid profiles between the groups after 3 years of intervention. It is difficult to compare our structured group education program directly with these two studies because of the different populations and this study concerned multiple sites and educators, as the intervention was delivered in 13 geographical locations with different genetics, cultural and lifestyle conditions. Supported by Tshianangasome et al. study showed that the effect of DSME on lipid profiles vary in different regions of the world. $^{19}$

The current study is in agreement with Moattari and colleagues, ${ }^{8}$ who approved the significant improvement of HDL in the experimental group compared to the control group after intervention respectively $(\mathrm{p}<0.05)$. However, no difference was seen in other metabolic indicators.

Regarding four areas of diabetes selfmanagement program; the present study showed that there was high statistically significant improvements in DSMQ scores of the intervention group before and after intervention $(\mathrm{P}<0.001)$. This was in accordance with a study in Ghana revealed that the higher the scores, the more effective one's self-care, also revealed that diabetes self-management program and good management of all four areas was associated with significant improvement of HbA1c, indicating good glycemic control. $^{20}$

Similarly, a study conducted in German diabetes center approved that the higher five scale scores of DSMQ indicate more desirable self-management behavior. ${ }^{10}$ In addition, another study by Azami et al. showed that DSME is cost-effective at improving self-management behaviors, self-efficacy and quality of life. ${ }^{21}$ A study in Turkey also, showed a significant improvement of DSM behavior among patients in intervention compared to those in control group. ${ }^{22}$

This study revealed that there were no statistical signification associations between DSMQ subscales scores and socio-demographic and clinical data of the intervention group except for diet control score, which was significantly higher among females and urban residents compared to males and rural residents. This may be attributed to that females more careful, maintaining their body shapes and less likely to be smokers. Regarding glucose management score, it was significantly higher among urban than rural residents. This might be caused by higher socioeconomic level and culture factors in urban than rural residents.

This was in agreement with study in Malaysia $^{23}$ that reported that sociodemographic and clinical characteristics of the participants were not associated with self-care behaviors except duration of T2DM; the patients with duration of T2DM less than one year and between six to ten years were found more likely to have inadequate self-care behaviors. Also study by Mutyambizi et al. who reported that Dietary diversity was associated with being female, higher socioeconomic status. $^{24}$

In addition, a study conducted in Sakaka City, Saudi Arabia showed that gender was significantly associated with multiple selfcare variables, including diet, exercise and heath appointment where male had more scores in relation to exercise and heath appointment and female had more score than male in relation to diet management. ${ }^{25}$ This difference may be related to the difference in the studied population as type 1 diabetes patients are younger than those 
having type 2 diabetes so they more motivated to maintain their healthy conditions, also females in Saudi Arabia may be less mobile due to cultural and religious factors. In contrast, to a study performed in India $^{26}$ reported that no significant differences found between specific diet self-care with sociodemographic factors.

\section{Conclusion and}

\section{Recommendations:}

In conclusion, the results of this study support the effectiveness of using the $5 \mathrm{~A}$ model of self-management educational program in the improvement of metabolic control indicators of T2DM patients in short time duration. So, it is recommended to perform self-management education by using the $5 \mathrm{~A}$ model for all individuals with diabetes in all primary health care settings. Further studies are recommended to determine the long-term effect of $5 \mathrm{~A}$ model of self-management on metabolic indicators of diabetes mellitus and need to reinforcement to maintain healthy behavior. In addition, studies include different social classes, patients attending both governmental and private sectors.

Limitation of this study: Application of DSMQ only for intervention group and not traditional one, short duration after intervention (3 months) to assess its effect. Small sample size taken can preclude the generalization of results.

\section{References}

1. International Diabetes Federation (IDF) Diabetes Atlas - 8th Edition. Online version of IDF Diabetes Atlas:www.diabetesatlas.org. 2017; ISBN: 978-2-930229-87-4.

2. Hegazy R and Mohamed E. Epidemiology Of and Risk Factors For Type 2 Diabetes In Egypt. Annals of Global Health. 2015; 81(6), Pp 814-820.
3. Meo S, Usmani A and Qalbani E. Prevalence of type 2 diabetes in the Arab world: impact of Gross Domestic Product and energy consumption. European Review for Medical and Pharmacological Sciences. 2017; 21: 1303-1312.

4. Pamungkas R, Chamroonsawasdi K, Vatanasomboon P. A Systematic Review: Family Support Integrated with Diabetes SelfManagement among Uncontrolled Type II Diabetes Mellitus. Behav. Sci. 2017; 7, 62; Doi: $10.3390 /$ bs 7030062 .

5. Davies MJ, D'Alessio DA, Fradkin J, Kernan WN, Mathieu C, Mingrone G et al. Management of hyperglycemia in type 2 diabetes, 2018. A consensus report by the American Diabetes Association (ADA) and the European Association for the Study of Diabetes (EASD). Diabetes Care. 2018;41(12):2669-2701. Doi:10.2337/dci180033.

6. Mikhael EM, Hassali MA, Hussain SA. Effectiveness of Diabetes Self-Management Educational Programs For Type 2 Diabetes Mellitus Patients In Middle East Countries: A Systematic Review. Diabetes Metab Syndr Obes. 2020 Jan 13;13:117-138. Doi: 10.2147/DMSO.S232958.

7. Silva Junior AJ and Gomes LC. Effects of an educational program focused on self-care and concurrent physical training on glycemia and drug treatment of patient with diabetes mellitus. Diabetes Updates, 2019. Volume 2(1):1-7. ISSN: 2631-5483. Doi: 10.15761/DU.1000116.

8. Moattari M, Ghobadi A, Beigi P and Pishdad G Impact of self management on metabolic control indicators of diabetes patients. Journal of Diabetes \& Metabolic Disorders.2012; 11:6 http://www.jdmdonline.com/content/11/6.

9. Glasgow RE, Goldstein MG, Ockene J, et al. Translating what we have learned into practice principles and hypotheses for addressing multiple behaviors in primary care. Ame J prev Med. 2004; 27(2suppl):88101.15275677[uid].

10. Schmitt A, Reimer A, Hermanns N, Huber J, Ehrmann D, Schall S, Kulzer B. Assessing Diabetes Self-Management with the 
Diabetes Self-Management Questionnaire (DSMQ) Can Help Analyze Behavioral Problems Related to Reduced Glycemic Control. PLOS ONE. March 3, 2016. DOI:10.1371/journal.pone.0150774.

11. Chai S, Yao B, Xu L, Wang D, Sun J, Yuan N, Ji L. The effect of diabetes selfmanagement education on psychological status and blood glucose in newly diagnosed patients with diabetes type 2. Patient Education and Counseling. 2018;101(8), 1427-1432. Doi:10.1016/j.pec.2018.03.020.

12. Fajriyah N, Firmanti TA, Mufidah A and Septiana NT. A Diabetes Self-Management Education/Support (DSME/S) Program in Reference to the Biological, Psychological and Social Aspects of a Patient with Type 2 Diabetes Mellitus: A Systematic Review. Jurnal Ners. 2019; 14(3si), 55-64. DOI: 10.20473/jn.v14i3(si).16979.

13. Reisi M, Javadzade H, Sharifirad G, Mostafavi F, Tavassoli E, Imanzad M. Effects of an Educational Intervention on Self-Care and Metabolic Control in Patients With Type II Diabetes. Journal of Client-Centered Nursing Care. 2017; 3(3), pp. 205-214. DOI: 10.32598/jccnc.3.3.205.

14. Gathu CW, Shabani J, Kunyiha N, Ratansi R. Effect of diabetes self-management education on glycaemic control among type 2 diabetic patients at a family medicine clinic in Kenya: A randomised controlled trial. Afr $\mathbf{J}$ Prm Health Care Fam Med. 2018;10(1), a1762. Doi.org/10.4102/phcfm.v10i1.1762

15. Safabakhsh L. The effect of an educational protocol based on pender's theory on lifestyle of patients after coronary artery bypass graft in Shiraz. [dissertation]. Shiraz University of Medical Sciences: Faculty of Nursing and Midwifery. 2004; In Persian.

16. Sadeghian HA, Madhu SV, Agrawal K, Kannan AT, Agrawal K. Effects of a selfmanagement educational program on metabolic control in type 2 diabetes. Turkish Journal of Medical Sciences. 2016; 46: 719726. Doi: 10.3906/sag-1501-115.

17. Davies MJ, Heller S, Skinner TC, Campbell MJ, Carey ME, Cradock S, Dallosso M, Daly H, Doherty Y, Eaton S, et al. Effectiveness of the diabetes education and self-management for ongoing and newly diagnosed (DESMOND) program for people with newly diagnosed type 2 diabetes: cluster randomized controlled trial .BMJ. 2008; 336:491. DOI: 10.1136/bmj.39474.922025.BE.

18. Khunti K, Gray LJ, Skinner T, Carey ME, Realf K, Dallosso H, Fisher H, Campbell M, Heller S, Davies MJ. Effectiveness of a diabetes education and self-management programme (DESMOND) for people with newly diagnosed type 2 diabetes mellitus: three year follow-up of a cluster randomised controlled trial in primary care. BMJ. 2012; 344:e2333. Doi: 10.1136/bmj.e2333.

19. Tshiananga JK, Kocher S, Weber C, Erny-Albrecht K, Berndt K, Neeser K. The effect of nurse-led diabetes self-management education on glycosylated hemoglobin and cardiovascular risk factors: a meta-analysis. Diabetes Educ. 2012;38(1):108-123. Doi: $10.1177 / 0145721711423978$

20. Apini R, Annan R, Apprey C, Boakye OA. Predictors of Glycaemic Control among Ghanaian Type 2 Diabetic Patients Using Diabetes Self-management Approach. International Journal of Biochemistry Research \& Review. 2018; 23(2): 1-18, Article no.IJBCRR.42976. DOI: 10.9734/IJBCRR/2018/42976.

21. Azami, G., Soh, K. L., Sazlina, S. G., Salmiah, M. S., Aazami, S., Mozafari, M., \& Taghinejad, H. Effect of a Nurse-Led Diabetes Self-Management Education Program on Glycosylated Hemoglobin among Adults with Type 2 Diabetes. Journal of Diabetes Research. 2018, 1-12. Doi:10.1155/2018/4930157.

22. Surucu HA, Kizilci S, Ergor G. The impacts of diabetes education on self-care agency, self-care activities and HbA1c levels of patients with type 2 diabetes: a randomized controlled study. Int J Caring Sci. 2017;10(1):479.

23. Ang1 J, Leo J, George $\mathrm{D}$, Chan $\mathrm{H}$. Inadequate Self-Care Behaviors among Malaysian Diabetic Patients: The Need for Action by Hospital Pharmacists. Journal of Pharmacy Practice and Community Medicine. 
2018;

$4(2): 51-54$

Doi:10.5530/jppcm.2018.2.14.

24. Mutyambizi1 C, Pavlova M, Hongoro C and Groot W. Inequalities and factors associated with adherence to diabetes self-care practices amongst patients at two public hospitals in Gauteng, South Africa. BMC Endocrine Disorders. 2020; 20:15. Doi:10.1186/s12902-020-0492-y

25. Hassan SME. Adherence to Diabetic SelfCare Activities in Adolescent and Factors
Contributing to Their Management within Sakaka City in Saudi Arabia. International Journal of Nursing and Health Science. 2017; 4(4): 37-45.

26. Mohandas1 A, Bhasin SK, Upadhyay M, Madhu SV. Diabetes self-care activities among adults 20 years and above residing in a resettlement colony in East Delhi. Indian Journal of Public Health. 2018; 62:104-10. DOI: 10.4103/ijph.IJPH_249_17.

\section{LIST OF ABBREVIATIONS}

\begin{tabular}{|l|l|}
\hline BMI & Body mass index. \\
\hline T2DM & Type2 diabetes mellitus. \\
\hline Hb A1C & Glycosylated hemoglobin. \\
\hline DM & Diabetes mellitus. \\
\hline IDF & International diabetes federation. \\
\hline NCD & Non-communicable diseases. \\
\hline DSME & Diabetes self-management education \\
\hline DSMES & Diabetes self-management education and support. \\
\hline FBS & Fasting blood sugar \\
\hline HDL & High-density lipoproteins. \\
\hline LDL & Low-density lipoproteins. \\
\hline CHOD/PAP & Cholesterol oxidase phenol 4-aminoantipyrine peroxidase. \\
\hline GPO/PAP & Glycerine phosphate oxidase peroxidase. \\
\hline DSMQ & Diabetes Self-Management Questionnaire. \\
\hline SD & Standard deviation. \\
\hline CI & Confidence interval. \\
\hline N & Number. \\
\hline DESMOND & $\begin{array}{l}\text { Effectiveness of the diabetes education and self-management for ongoing and } \\
\text { newly diagnosed (DESMOND) people with type 2 diabetes. }\end{array}$ \\
\hline
\end{tabular}

